\title{
Suffering and Punishment
}

\author{
MICHAEL S BRADY*
}

\section{Introduction}

Suppose one thinks that judicial punishment is sometimes appropriate. Suppose one also thinks that appropriate punishment necessarily imposes burdens or hard treatment on the criminal. Suppose, finally, one thinks that in order to be genuinely burdensome, the wrongdoer needs to suffer. The resulting account of just punishment raises a host of interesting and important questions concerning the relation between the negative emotions that constitute suffering, punishment, the rights of offenders, and sentencing. Perhaps the most important concerns the final supposition, and asks: Why must hard treatment take the form of imposing suffering? A plausible answer to this question, according to those who support the Communicative Theory of Punishment, will appeal to the communicative value that such imposition has. On this view, the imposition of suffering constitutes a legitimate form of censure for wrongdoing, wherein the state communicates to the offender the seriousness of his or her wrongdoing. At the same time, hard treatment, in the form of suffering, provides the opportunity for and enabling conditions in which wrongdoers can come to recognise the nature of their wrongdoing, repent, make reparations, and reform themselves. Suffering thus provides the means by which wrongdoers can make amends to those they have wronged - who are owed repentance and reparations - and also restore their own moral balance and character. Of course, the theory does not hold that suffering necessarily brings about these goods, or any others. Clearly, the suffering imposed by the judiciary can have no positive effect, and indeed can (and often does) make things considerably worse, for the offender and for society as a whole. Nevertheless, the communicative

\footnotetext{
* A version of this chapter was presented at the Virtue, Emotion and Imagination in Legal Reasoning conference at the Institute for Philosophical Research, UNAM, in March 2017. I would like to thank the speakers and delegates at this conference for their helpful feedback. I would like to especially thank the organisers of the conference - Maksymilian Del Mar and Amalia Amaya - for inviting me to this event, and for their very helpful comments on an earlier draft. Some of the ideas about the importance of suffering for justice here are developed from Chapter 5 of my Suffering and Virtue (Brady, 2018). This itself was the result of the Value of Suffering Project, funded by the John Templeton Foundation, which ran in Glasgow from September 2013-May 2016 (Grant ID 44167).
} 
theorist argues that suffering is extremely important for the provision of these goods, in the sense that they would not be achieved in its absence.

This account faces a number of objections concerning the necessity of hard treatment, in the form of suffering, for the achievement of the stated goods. In this chapter I will examine two of the most pressing worries, raised in a recent paper by Matt Matravers. These are (i) that suffering is not needed for censure and (ii) that the imposition of suffering can lead to unfair sentencing. After outlining the objections, I will suggest how the communicative theorist can respond, by invoking the idea that censure requires the expression of appropriate emotions, and the actions that are part and parcel of these. Hard treatment is thus warranted as an expression of appropriate emotion.

\section{Suffering as Ensuring Just Punishment}

It is something of a platitude in moral philosophy that pain and suffering are bad; indeed, it would be difficult to find a more obvious candidate for intrinsic disvalues than these. Hedonists are surely right about this, even if we can doubt that pain and suffering are the only things that are intrinsically bad. However, pain and suffering also have great (extrinsic) value: those who are pain insensitive don't live very long; we might say something similar about those who are unable to feel fear. Feelings of shame and guilt would seem to be essential to co-operative living with others; feelings of disappointment have great motivational force in getting us to do better next time. And so on.

We might think that suffering is valuable from the social perspective in another important way: namely, suffering is an appropriate form of payment for wrongdoing. Here suffering has value as coin. This claim is most straightforwardly understood in religious traditions as the idea that suffering is just punishment for sin. But the claim has obvious secular counterparts when we look at judicial punishment. Here many people think that pain and suffering are valuable because they are an essential part of punishment, and so an essential element in the proper functioning of society itself. To see this idea in more detail, let us look more closely at the nature of punishment, and make the case for a particular account of the justification of the imposition of suffering in punishment, namely the Communicative Theory.

What is punishment? In Leviathan, Thomas Hobbes wrote that 'punishment is an evil inflicted by public authority on him that hath done or omitted that which is judged by the same authority to be a transgression of the law, to the end that the will of men may thereby the better be disposed to obedience.' In 1968, HLA Hart defined punishment as involving five necessary conditions:

(1) it must involve pain or other consequences normally considered unpleasant;

(2) it must be for an offence against legal rules;

\footnotetext{
${ }^{1}$ Hobbes (1651/2008).
} 
(3) it must be of an actual or supposed offender for his offence;

(4) it must be intentionally administered by human beings other than the offender;

(5) it must be imposed and administered by an authority constituted by a legal system against which the offence is committed. ${ }^{2}$

A more contemporary definition yet is due to Hugo Bedau and Erin Kelly in the Stanford Encyclopedia of Philosophy: judicial or criminal punishment is 'the authorized imposition of deprivations - of freedom or privacy or other goods to which the person otherwise has a right, or the imposition of special burdens - because the person has been found guilty of some criminal violation, typically (though not invariably) involving harm to the innocent. ${ }^{3}$

There are a number of important common elements in these definitions, which I assume go to the heart of our thinking about what punishment is. But for our purposes, the most significant one is that punishment for wrongdoing, in the form of illegal or criminal acts, involves the imposition of pain or unpleasantness, deprivation or burdens. (Sometimes this is referred to as 'hard treatment', and includes, as Antony Duff puts it in his 2018 Stanford Encyclopedia article, 'material impositions or exactions that are in themselves typically unwelcome: they deprive people of things that they value (liberty, money, time); they require people to do things that they would not normally want to do or do voluntarily (to spend time on unpaid community labour, to report to a probation officer regularly, to undertake demanding programmes of various kinds). ${ }^{4}$ )

It is thus tempting to think that the legal/secular model of punishment is defined as necessarily involving the imposition of suffering onto the guilty, in the sense of some negative affective state of a suitable intensity. Now it might be objected here that negative affect need not be involved; the deprivations that Bedau and Kelly and Duff cite - of freedom and privacy and similar goods - are not themselves instances of negative affect or experienced suffering. Nevertheless, I take it that such losses only count as losses and as genuine deprivations for the subject insofar as they are experienced as burdens by the subject: that is, in a way that essentially involves negative affect. This explains our intuitions about the injustice of punishing the very rich with fines or other financial penalties. Such things will only count as losses or as burdensome insofar as the rich care about what is lost, and in the case of fines they typically don't. As a result, whilst punishment ought not to involve the imposition of physical pain on criminals, punishment is of its essence meant to be burdensome, and it is difficult to see how something can be a burden unless it is experienced as such by the wrongdoer. So legal punishment involves the intentional imposition, by the appropriate authority, of suffering on the wrongdoer.

\footnotetext{
${ }^{2}$ Hart (1968) 4-5.

${ }^{3}$ Bedau and Kelly (2015).

${ }^{4}$ Duff and Hoskins (2018).
} 
This is what punishment is. It's another question whether the imposition of suffering by legal authorities is ever justified or appropriate. This is something which traditional retributivist accounts of punishment have had great difficulty in explaining, and a central reason why this approach to punishment fell out of favour in the twentieth century. As Matt Matravers writes, the reason for the theory's 'moribund state was that retributivism seemed to be plagued by a blank space where an argument was needed. Specifically, the retributive claim that "past wrongdoing (by an offender) justifies present suffering (inflicted on that offender for that wrongdoing)" appears to be either deeply mysterious or meaninglessly circular. ${ }^{5}$ However, a recent development of a retributivist theory - the Communicative Theory of Punishment - fares much better on this account. In what follows I will outline how the communicative theory explains the appropriateness of punishment, in a way that highlights the importance of suffering in achieving punishment's legitimate aims.

At the heart of the communicative theory is the idea - as the name suggests that punishment is essentially a communicative enterprise, and that the ultimate justification for the imposition of suffering is that it serves a communicative purpose. This view accommodates both retributivist and reformist thinking, since (i) what is communicated in punishment is something merited or deserved by the criminal, and (ii) an internal goal of such communication is that the criminal recognise and acknowledge their wrongdoing, repent, make reparations, and reform themselves. To see the theory in more detail, let us turn to the work of perhaps the best-known communicative theorist, Antony Duff; in what follows I focus in the main on his monograph Punishment, Communication, and Community. ${ }^{6}$

Duff is concerned to argue against both consequentialist and 'pure' retributivist accounts of punishment. The former, he proposes, are ultimately inconsistent with acknowledging the rights of the innocent and the guilty, and as such will not ensure justice. The latter, on the other hand, fail to provide a plausible answer to the questions of why the guilty deserve to suffer. We can reject the retributivist line that wrongdoers deserve to suffer because this is a way of ensuring the social value of fairness. This, Duff argues, is implausible, because it 'offers a distorted picture of the punishment-deserving character of crime.7 The wrongs of physical assault or arson, for instance, clearly don't consist in taking unfair advantage of the law-abiding or in being a free-rider. By the same token, the idea that punishment is a matter of paying back what one owes is problematic: murder victims are unable to be recompensed for their loss, and a murderer doesn't (arguably) owe the state recompense. Moreover, there are many criminal activities that are not characterised as a form of profit-making, and punishment for these is again poorly understood as a kind of paying back. Think again of physical assault or arson. So standard retributivist attempts at explaining why the wrongdoer deserves to suffer fail.

\footnotetext{
${ }^{5}$ Matravers (2011), 69.

${ }^{6}$ Duff (2001).

${ }^{7}$ Ibid, 22.
} 
Duff maintains that punishment has a different function to that of deterring crime or ensuring fairness. Instead, he thinks that legal punishment serves to communicate 'the condemnation or censure that criminals deserve' for their crimes. ${ }^{8}$ Such condemnation is required by the state's concern for the rights and values that its laws are set up to protect, since failure to condemn implies that the state does not mean what it says when it prohibits certain activities. It is in this sense that punishment, as a form of condemnation and censure, is merited or deserved: it follows from the state's commitment to the rights and values that the legal and judicial system are set up to protect and preserve, and the criminal's violation of these rights and undermining of these values. In addition, by condemning and censuring criminal activity, the state also communicates concern for and solidarity with the victims of crime, and a willingness to punish others who break the law. These too would seem to be implications of a genuine commitment to the values at stake. ${ }^{9}$

Consider, in this light, the sentencing remarks made by Lady Rae in the High Court in Glasgow, upon sentencing Tanveer Ahmed for the murder of Assad Shah:

It is clear from the agreed facts presented to me that this was a barbaric, premeditated and wholly unjustified killing of a much loved man who was a pillar of the local community ... Let me be clear, no one in any civilised country including Scotland has the right to take the life of another, whatever offence that individual perceives that he or she has suffered. It is vitally important in modern society that respect and tolerance for others of every race, creed, colour, ethnic origin or religious belief is maintained and protected by the law of the land ... I shall have regard to the various factors put forward as mitigation but none of them can truly mitigate, to any great extent, the brutality of your actions; the premeditation and motive behind those actions; your lack of remorse and your pride in what you did. For all of these reasons I intend to impose an exemplary sentence. ${ }^{10}$

Lady Rae's words here clearly condemn the offender for his offence, in a way that expresses censure in the strongest terms, respect for the values that the offender violated, and a clear willingness to punish as a result. (As we'll see later, it is plausible to think that the words also express strong emotions on Lady Rae's part, and at the same time generate, through imaginative engagement, emotions in those who hear or read them. It is not implausible to therefore view Lady's Rae's sentencing as a part of a pattern of emotional expression for the values that have been violated by this crime.)

Insofar as punishment communicates the censure that criminals deserve, it captures the retributivist intuition that punishment should be 'backwardlooking', and address itself to the fact and nature of what a criminal did. But the retributivist element is only a part of the communicative theory, since the

\footnotetext{
${ }^{8}$ Ibid, 27.

${ }^{9}$ The issues of care and concern, and their relation to valuing lives, is the focus of Blum (2020) (chapter seven in this volume).

${ }^{10}$ At http://www.scotland-judiciary.org.uk/8/1639/HMA-v-Tanveer-Ahmed.
} 
theory also wishes to accommodate the intuition that punishment should also be 'forward-looking' and thus aim at reforming offenders. Duff explains this element by noting that the communication of censure treats the offender as a rational agent, and in doing so aims to promote a particular kind of response. (It is part of the nature of communication to regard the other person in this way.) In particular, the offender 'is expected (but not compelled) to understand and accept the censure as justified: to understand and accept that he committed a wrong for which the community now properly censures him. His trial and conviction thus address him and seek a response from him as a member of the political community who is both bound and protected by its laws. ${ }^{\prime 11}$ By communicating censure and condemnation in this way, the state hopes that the offender will come to understand and recognise his wrongdoing and to repent for his offences; moreover, the state hopes that the offender will, as a result of such recognition, be moved to make reparations to the victim, and to commit to reforming himself so that he does not behave that way in the future. Just as the state's concern for particular values commits it to condemn acts that violate such values, so too does the criminal's acknowledgement and understanding of his wrongdoing commit him to repentance, the making of reparations, and reformation. For without the latter commitments, we can doubt that the offender really does acknowledge and recognise that he did something wrong, or really does understand what he did.

Legitimate or justified punishment therefore aims at giving criminals what they deserve, and at persuading them to recognise and acknowledge their wrongdoing, to repent, and reform. Still, we have yet to see exactly why censure, in the form of suffering, is essential for communication. What, in other words, is the justification for imposing hard treatment on criminals? Why must we communicate and motivate reform by making offenders suffer losses and deprivations?

There are two strands to the communicative theorist's answer to these questions. One focuses on the suffering necessarily involved in acknowledging and accepting one's wrongdoing. For Duff, 'an authentic recognition that I did wrong must bring with it repentance of that wrong. I recognize and own it as mine I do not deny it or seek to justify or excuse it. But I also disown it, as something that I should not have done and now wish I had not done. Repentance is necessarily painful, since it must pain me to recognize and admit (to myself and others) the wrong I have done. In aiming to induce repentance, punishment thus aims to bring offenders to suffer what they deserve to suffer - the pains of repentance and remorse. ${ }^{12}$ On this view, suffering, in the form of feelings of remorse, is an essential part of the recognition and reform that punishment aims to bring about. In a paper from 2003 called 'Probation, Punishment and Restorative Justice', Duff continues this idea, stating that 'censure must aim to produce pain, in that if the person is not pained by it, it has failed to achieve its aim. That aim is not, of course, simply to cause or induce pain: it is to induce the appropriate

\footnotetext{
${ }^{11} \operatorname{Duff}(2001), 80$.

${ }^{12}$ Ibid, 107. (My emphasis.)
} 
kind of pain - the pain that is intrinsic to accepting criticism from one's fellows and, even more importantly, the pain that is intrinsic to the recognition that one has wronged someone.' ${ }^{13}$

The other focuses on a different kind of burden and deprivation that the state intentionally imposes, namely community service, or probation, or some other burdensome reparative work. ${ }^{14}$ Here the communicative theorist appeals to different but related ideas about the nature and function of communication involved in censure and condemnation. One idea is that censure and condemnation that is expressed verbally - for instance, by a guilty verdict and judge's summing up of the offender's wrong in a court of law - fails to constitute the kind of censure or condemnation that we need. Duff writes:

With more serious wrongs, mere words cannot suffice: they cannot suffice to express, or to assure others of, the offender's repentant recognition of what she has done, any more than they can suffice to communicate to the offender the censure that she deserves. Punishment can then constitute a more forceful communication both of censure to the offender, and of apology to those whom she has wronged. ${ }^{15}$

The thought here would seem to be that the imposition of hard treatment is indeed necessary for the communication of censure; for communication has to be suitably forceful, and only hard treatment can supply the requisite force.

The second idea is that hard treatment in the form of suffering has important effects on attention, and this can play a significant role in bringing about repentance and the other goods in question. ${ }^{16}$ This is because suffering focuses and captures attention, and in so doing makes it both difficult to ignore some important or significant object or event, and motivates reflection about that object or event. The suffering of hard treatment helps to ensure that the criminal cannot (so easily) ignore his criminal activity and his wrongdoing. As Duff points out:

When I have done wrong, it is often tempting and all too easy to distract myself from the fact. I might say, to myself or to others, 'Yes, I did wrong and am sorry for it.' I might think that I have now repented the wrong. But all too often I have not seriously repented, because I have not thought seriously enough about, that wrong ... Repentance, at least with serious wrongs ... must go deep with the wrongdoer and must therefore occupy his attention, his thoughts, his emotions, for some considerable time. ${ }^{17}$

So another function of the imposition of burdens on the offender is 'to focus his attention on his crime', and ensure that repentance is suitably deep. Here suffering plays a similar attention-directing role to that played by physical pain or forms of

\footnotetext{
${ }^{13} \operatorname{Duff}(2003), 186$.

${ }^{14}$ Duff is resistant to the idea that imprisonment and fines are appropriate forms of censure, and he thinks that we need to think of more humane and effective forms of condemnation. See Matravers (2011), 76.

${ }^{15} \operatorname{Duff}$ (2003), 189.

${ }^{16}$ For a discussion of the role of emotion in motivating attention to legal questions, and in particular the attention of judges to matters of law, see White (2020) (chapter six in this volume).

${ }^{17}$ (2001), 108.
} 
emotional suffering: just as physical pain rules out the option of easily ignoring putative sources of physical damage, so too does the suffering in legitimate forms of judicial punishment keep the offender's criminal wrongdoing in mind. So, at the very least, hard treatment makes it difficult for the criminal to ignore his wrongdoing, and ignore how seriously this kind of wrongdoing is regarded by the state and his fellow citizens. ${ }^{18}$

There is another connection between suffering and attention that is important here. For suffering not only directs attention, but captures attention, and this helps to facilitate - at least in the right circumstances - an imaginative engagement with, and an understanding of, emotional objects and events. ${ }^{19}$ By making the criminal suffer, therefore, the state puts in place conditions for the criminal to reflect and deliberate on what he did, in part through imaginatively engaging with the harm his wrongdoing caused to his victim, with what his victim felt, with the kind of reparations that might be appropriate, and with a future existence where his wrongdoing has been addressed and his moral character repaired. In this way the wrongdoer will hopefully come to recognise and understand the nature of his wrongdoing, understand the effect it had on his victim, understand what he needs to do, and understand the shape his life from hereon has to take. As Duff puts it, penal hard treatment 'provides a structure within which, we hope, [the criminal] will be able to think about the nature and implications of his crime, face up to it more adequately than he might otherwise (being human) do, and so arrive at a more authentic repentance. As fallible moral agents, we need such penances to assist and deepen repentance. ${ }^{.20}$

That suffering provides the opportunity for focused attention and imaginative engagement does not, of course, mean that it will bring about recognition, repentance, reform and reparations. Sometimes - perhaps often - wrongdoers will seek to shift the blame elsewhere. The wrongdoer might believe, therefore, that he suffers because he is the victim of the judicial system, or his upbringing, or the police, or society in general. Such rationalising explanations of why he is being so deprived are doubtless common amongst those who suffer judicial punishment. But this need not be the outcome of suffering's imposition. Instead, sometimes a criminal will come, through having his attention fixed on his wrongdoing and on how seriously the state takes this violation of these laws, to a recognition and an understanding of his wrongdoing, and of the steps he needs to take to rectify it. So in some instances at least, suffering imposed will motivate acknowledgement and

\footnotetext{
${ }^{18}$ In his Stanford Encyclopedia entry on 'Legal Punishment', Duff writes: 'Punishment ... should aim not merely to communicate censure to the offender, but to persuade the offender to recognise and repent the wrong he has done, and so to recognise the need to reform himself and his future conduct, and to make apologetic reparation to those whom he wronged. His punishment then constitutes a kind of secular penance that he is required to undergo for his crime: its hard treatment aspects, the burden it imposes on him, should serve both to assist the process of repentance and reform, by focusing his attention on his crime and its implications, and as a way of making the apologetic reparation that he owes.

${ }^{19}$ For more on this, see Brady (2013).

${ }^{20} \operatorname{Duff}(2001), 108$.
} 
understanding, and the repentance and remorse that are a part of these. The point here, then, isn't that suffering will necessarily bring about a valuable end. Nevertheless, the understanding that is central to repentance and reform will be, for fallible agents like us, highly unlikely without the focused attention and imaginative engagement that suffering brings. If the state wants to achieve these valuable social goods, therefore, it will have to make criminals suffer.

So, at least, the communicative theory maintains. But there are worries about this approach to the justification of hard treatment. In the following section I will examine two such worries, and show how the communicative theorist can appeal to the connections between censure and emotion in order to respond.

\section{Are Words Sometimes Enough?}

In a recent paper, Matt Matravers has raised worries about the need for suffering in legitimate punishment, and in particular about Duff's explanations of its importance. Matravers makes two related criticisms. ${ }^{21}$ The first is that suffering is not necessary for censure - on the grounds that sometimes words are enough and so the censure at the heart of the communicative theory, and the imposition of suffering, can diverge. If this is the case, then a second criticism becomes germane: in many cases, the imposition of suffering will then be unfair, since those who come to acknowledge their wrongdoing, repent, reform themselves, and make reparations as a result of verbal censure alone will be unfairly punished by further impositions such as probation or community service. Let us take these criticisms in turn.

(i) Matravers begins by noting that on Duff's view, punishment is an intrinsically appropriate response to crime. This is because wrongdoing deserves moral criticism or censure, and wrongdoing of a certain kind is serious enough that it merits or deserves censure by the state. But Matravers notes that 'the common or garden way in which one communicates censure or gratitude is by using certain words or phrases. ${ }^{22}$ And it is at least possible, he thinks, that communication of this sort can succeed in bringing about the suffering at which punishment aims: namely the pain and suffering that is intrinsic to accepting the criticism and condemnation of others, and recognising the wrongs that one has done. Matravers writes:

The claim is that sometimes words cannot suffice to communicate to the offender the censure that she deserves. But, why? It cannot be that we genuinely cannot think of words that will do the job ... a combination of the richness of language and the fact that (as Duff emphasizes) this is a two-way communication in the context of a wrong done, makes me skeptical about applying the everyday thought that sometimes "words are not enough" too quickly to these cases. ${ }^{23}$

\footnotetext{
${ }^{21}$ Matravers (2011).

${ }^{22}$ Ibid, 75 .

${ }^{23}$ Ibid, 78 .
} 
Now even if it is the case that some people might come to fully accept the criticism and come to fully recognise and understand their wrongdoing, this is surely not true for most people. In these cases, Matravers notes that 'it takes more than just verbal expression to focus one's mind on what one has done. A repeat wife-beater may need not merely to hear censure, but to feel it, and he may need time over which to think through what he has done. ${ }^{24}$ This is where the second dimension of Duff's approach to the imposition of suffering comes in: for many or most offenders suffering 'provides a structure within which, we hope, [the offender] will be able to think about the nature and implications of his crime, face up to it more adequately than he might otherwise (being human) do'. But Matravers thinks that this is also problematic. For in cases such as these, it is much harder to see that censure is simply being expressed in hard treatment and the latter is thus intrinsically appropriate. Rather, it seems more natural to say that the offender has failed, or will fail, to appreciate the appropriate censure and so hard treatment is deployed to focus his mind on the censure that would otherwise be appropriately only verbal. ${ }^{25}$ So hard treatment - in the form of community service, probation, etc - is not itself part of or intrinsic to the censure or condemnation. Instead, it is best regarded as a valuable way in which the offender's mind can be focused on the state's censure or condemnation, in the hopes that he will take it to heart and come to recognise and acknowledge his wrongful behaviour. If words can be enough for censure, therefore, then coerced punishments such as probation and community service are not the vehicles through which censure is expressed.

(ii) This gives rise to the second worry - one that has been raised before against accounts of punishment that appeal to a 'subjective' component like suffering. ${ }^{26}$ The worry is that the communicative theory - indeed, any account that appeals to the necessity of suffering for punishment - will lead to unfair and hence unjust punishments, and differential treatment for the same crimes. Matravers puts the argument as follows:

Once censure and the hard treatment needed to ensure the censure is heard are decoupled, then differential punishments will result. Some offenders will grasp immediately the full force of the wrong that they have done. For reasons to do with the need to reassert the values of the community and to express the appropriate censure, the state must of course nevertheless censure them. However, why should that censure take a nonverbal form? One answer is that it is proportionate to the censure expressed in other cases where hard treatment was needed. But this looks as if the level of hard treatment appropriate as censure will be dictated by the offender who is least able to respond to verbal signals and that surely cannot be right. Duff, I think, would say that the mistake here is to think of censure and hard treatment as two things and not one. The appropriate censure for a given offence just is what it is, and if that means words are not enough then words are not enough. However, as noted above, it is hard to grant that claim.

\footnotetext{
${ }^{24}$ Ibid, 79.

${ }^{25}$ Ibid.

${ }^{26}$ See, for instance, David Gray (2010).
} 
Words are enough to express censure of all kinds, but sometimes they are not enough to be heard. That, though, returns us to the baseline of the most thick-skinned offender. ${ }^{27}$

The thought is, therefore, that it is possible that some offenders will, when facing censure from the state, quickly recognise the wrongness of their behaviour, repent, commit to reforming themselves, and make appropriate reparations. Other offenders will not. Since the state needs to ensure parity of sentencing, and assure the community that we treat like cases alike, the state must impose the same hard treatment, in the form of coercive punishments, on those who accept the censure and repent, and on those who do not. But this seems both unfair to those who have 'heard' the censure and accepted it, and contrary to the aims and spirit of the communicative theory. For in the former case, communication of censure has worked and the aims of the theory have been achieved. Any further imposition of hard treatment would therefore only be warranted on other - possibly consequentialist - grounds. (This is Matravers's suggestion on $\mathrm{p} 80$, where he is worried that such imposition is a matter of using that person 'as a means to other ends'.) If so, then the communicative theory is both unfair, and inconsistent with its own requirements.

In the following section I will argue that the communicative theorist can respond to both of these worries, by focusing on the importance of emotion for sincere and forceful communication.

\section{The Role of Emotion in Censure and Condemnation}

Matravers thinks that words can be enough to express censure and condemnation, and that as a result censure and hard treatment can be decoupled. I think that he is wrong on the first count and (therefore) wrong on the second as well. For a condition on the successful expression of censure and condemnation is the presence of appropriate emotions, and the suite of evaluations, feelings, facial and bodily expressions, and actions that are their constituents. 'Saying the words' is only part of this suite, only part of what is really called for by the wrongdoing or offence. As a result, words are not enough to express censure: other elements, including actions that constitute hard treatment, need to be in place. Since this is all rather abstract, let me explain by appeal to a non-judicial case of wrongdoing and censure, the kind of thing that can happen in a loving relationship. ${ }^{28}$

Imagine that Alice and Ted are in a long-term relationship; indeed, they are thinking of getting married, raising a family, and are looking forward to

\footnotetext{
${ }^{27}$ Matravers (2011), 79.

${ }^{28}$ The importance of emotions, and in particular of empathy, for intimate relationships is examined in Hansberg (2020) (chapter nine in this volume). My example focuses on the role that negative emotions have in such relationships, when it comes to expressing condemnation and motivating appropriate behaviour.
} 
spending the rest of their lives together. Six months before the wedding, at a Christmas party, Alice catches Ted kissing one of their friends, Carol, and experiences a range of emotions: anger, hurt and contempt are prominent here. Confronting Ted later that evening, Alice expresses these emotions in a variety of ways. She condemns Ted's appalling behaviour, tells him how let down she feels, and how shocked that he would do this. There are tears, curses, insults. Ted, mortified, apologises profusely, and genuinely feels terrible. He reiterates his commitment to Alice, promises never to do anything like this again, and begs Alice to forgive him. Alice, though still deeply hurt, believes Ted. Nevertheless, the next few weeks are marked by temporary changes in their relationship: Alice gives Ted the 'cold shoulder', refuses physical contact, is often abrupt and cutting in her remarks to him, and insists that he spends time away from the flat that they share together. She insists that they go to couples counselling if the wedding is to go ahead, in order that Ted comes to think about and understand himself and his wrongdoing more clearly. Ted is, for his part, motivated to be a better person: to be kinder, more considerate, more committed, more loving, to Alice. After a sufficient amount of time, their relationship takes on something like the shape it did before Ted acted so badly. Indeed, in some ways the relationship is stronger and deeper, although in other ways it has been damaged by the affair.

Suppose we now ask: what is needed for Alice to express her censure and condemnation to Ted? In this instance, would words be enough? Clearly, Alice's simply saying the relevant words - 'How could you do this to me? You heartless bastard', and so forth - isn't enough to express censure. Alice might after all say the words in a flat, bored manner, in a tone that expresses her lack of concern about the values that Ted's behaviour has damaged. At the very least, Alice will have to say the words in way that expresses or reflects her anger, hurt and disappointment. Her words will, in other words, have to express her emotions if they are to genuinely express censure and condemnation. ${ }^{29}$ This isn't merely an epistemic point - that Ted won't believe that Alice thinks he behaved wrongly, in the absence of an exhibition of her emotions on her part - although that is surely true. It's the substantive point: that Alice's words won't express censure at all unless they are the vehicle for the emotions generated by and themselves warranted by Ted's wrongdoing. For it is not just censure, in the form of words, that Ted's wrongdoing merits. It also merits the whole range of Alice's emotions - her anger, hurt, disappointment, sadness, and the like. Such emotions are not merely expected in response to Ted's betrayal. Instead, they are normatively called for: they are warranted, fitting, justified, appropriate, rational responses, so that someone who didn't feel as Alice feels in the relevant circumstances would violate the relevant norms, and might well be criticisable for this reason.

\footnotetext{
${ }^{29}$ This point will be familiar to, and readily accepted by, internalists about moral judgements, who maintain that sincere moral judgement is essentially linked with motivation. On that account, those who 'say the words' but lack any motivation to act accordingly don't really make moral judgements. See Smith (1995), for this line. Here I'm making a similar point, but focusing on the necessity of emotional responses for sincere or legitimate censure and condemnation.
} 
How can Alice's words be the vehicle for her warranted emotional response? It seems to me that this can only be the case if her verbal expression also expresses other emotional elements or aspects. Emotions typically involve facial and bodily expressions, and Alice's words need to be accompanied by the relevant facial and bodily movements associated with anger and hurt, therefore. By the same token, Alice's words will need to express her affective state - how she feels - and so will have to have a particular tone or force. Again, these are not merely epistemic points - that Ted won't believe that Alice thinks he behaved wrongly, in the absence of the relevant facial expressions and feelings on her part - although this is also surely true. It's the substantive point: that Alice's words won't express censure at all unless her expression of them embodies the facial and bodily and affective elements that are characteristic of anger, hurt, and the like. To be sure, some of these might be subtle: a slight change in the tone of voice, a stiffening of the posture, a downturn of the mouth, a narrowing of the eyes - these can all convey or express anger, and so bodily and facial expressions don't have to be as overt as they would be in the case of someone who is 'pure ragin', to use the excellent Scottish phrase. Still, it would be difficult to understand how Alice's words can express censure in the absence of any facial and bodily changes, and in the absence of any feelings on her part. It is certainly difficult to see how any verbal expressions could be forceful, in the absence of these emotional components.

This paves the way for a response to Matravers. For it is plausible to claim that expression of censure equally requires the appropriate behaviour on Alice's part. Could Alice express censure and condemnation to Ted without giving him the cold shoulder, without breaking off physical contact, and the like? Consider how anomalous her angry words, and angry facial and bodily postures, would be if Alice immediately welcomed his apologies with warm embraces, if their loving intimacy resumed without pause, if there were no period at all where Ted was shunned, left alone to think and reflect on what he'd done, to stew in his misery. This suggests not simply that Alice's behavioural responses are normal or typical responses to infidelity; instead, they are what is to be expected in the normative sense, where the absence of such responses would again be anomalous and indeed criticisable. (Imagine how Alice's friends would react if Alice failed to give Ted the cold shoulder, at least for a while. Wouldn't they - and we - be inclined to think that Alice isn't acting as she ought, that she is perhaps lacking in self-esteem to some degree, or too dependent upon or reliant on Ted for her own good?) If so, then we might claim that certain patterns of behaviour are required if Alice is to appropriately express censure and condemnation of Ted's actions. It isn't enough for her to say the words, to say them with emotion, and to look as though she means them; she has to act as though she means them as well, and so her behaviour will have to follow suit for her expression to be genuine. If so, then (forceful) expression of censure and condemnation requires the appropriate words, said with feeling, expressed by the appropriate facial and bodily expressions, and accompanied by particular and fitting patterns of behaviour. The relevant actions, in other words, are not mere focusing devices whereby 
Ted is given the opportunity to reflect and repent. Instead, they are part of what (forceful) censure and condemnation is.

The application to the judicial case should, I hope, be reasonably clear. The state's censure and condemnation of an offender cannot consist in merely 'saying the words', no matter how rich the language involved, if we think that the words must also express the appropriate emotions. Here, too, I assume that the appropriate emotions are (legitimate) anger, with a wide range of other emotional possibilities: perhaps contempt; perhaps moralised disgust in the case of particularly reprehensible crimes. Judicial condemnation must reflect and express the (legitimate) feelings of the state: feelings that are fitting when its laws are violated and its values undermined. As with the case of a loving relationship, this isn't merely an epistemic point - that the offender won't believe that the state thinks he acted wrongly, in the absence of the underlying emotions and their expression in the courtroom - although this is also surely true. It is the more substantive point: that the court's words won't express censure at all unless they are accompanied by the emotions, and emotional expressions, that are characteristic of moralised anger and hurt. At the very least, it is difficult to see how any verbal expression of censure could be suitably forceful in the absence of emotions and their elements.

Given all this, we can claim that the state's (forceful) expression of censure requires appropriate action on the state's part. Indeed, we might think that appropriate action is the most obvious and most effective way in which the state can express emotion, and so express what the offender deserves. (It is less easy to see how the state could convey particular facial expressions or other emotional components.) Just as Alice's expression of censure and condemnation of Ted's actions required a certain pattern of behaviour that is meant to be burdensome for Ted - that is intended to make Ted suffer in addition to his pains of remorse and regret - the state's expression of censure and condemnation of criminal offences likewise require the imposition of hard treatment on the offender. Anything less than this makes the state itself liable to criticism, in much the same way that Alice is liable to criticism should she fail to impose burdens on Ted as a result of his actions. The imposition of hard treatment on to criminals is not a mere focusing device; it is, on this view, intrinsic to the censure that the offender deserves.

Now there are, of course, clear differences between the case of Alice and Ted, and the case of the state's imposition of hard treatment on someone who commits a criminal offence. It might be claimed, for instance, that the state is not the kind of thing that can have emotions, and hence not the kind of entity that can express them in words or actions. It doesn't make sense, therefore, to talk as if the state's censure is only legitimate insofar as it expresses the state's anger etc. However, claims like this about the possibility or otherwise of group emotions are clearly controversial, and so provide questionable grounds for detaching state censure and hard treatment. After all, we often talk as if groups, indeed states and nations, have emotions: we naturally say things like the following: that the country is ashamed 
of its wartime conduct, the citizenry are anxious about the state of the economy, the nation is overjoyed at winning the World Cup, the populace is in mourning over the death of the princess. And whilst it might be plausible to deny that states or collectives can have genuinely shared feelings or affective experience, it is much less plausible to deny that states can have collective beliefs, collective values, and engage in collective action. Indeed, the claim that the state takes seriously violations of its laws, that it respects all of its citizens, and so forth, only makes sense if we think that the state is the kind of thing to which we can attribute values, cares and concerns. It is hardly a stretch, therefore, to think that states can express things like anger when its laws are violated. ${ }^{30}$

A second worry is more serious, and might nudge us towards a weaker response on behalf of the communicative theorist. The worry is that arguably only some emotional elements need to be in place for censure to be expressed, rather than all, and so censure need not require action. There are, after all, emotions without particular behavioural expressions - some aesthetic emotions, for instance wonder, might be like this - and so it is not true that all emotions require expression in action as well as words. Might it not be possible, therefore, for Alice to express censure of Ted's behaviour by verbal means alone? If so, then censure and the imposition of hard treatment can come apart. By analogy, the state can succeed in censuring an offender by saying the relevant words in a court of law in a way that expresses the state's seriousness and anger, without imposing hard treatment in the form of probation, community service, and the like. Hard treatment is not, on this view, intrinsic to censure.

As we saw, Matravers thinks that this leads to problems for the communicative theorist. Matravers asks: 'why should ... censure take a non-verbal form? One answer is that it is proportionate to the censure expressed in other cases where hard treatment was needed. But this looks as if the level of hard treatment appropriate as censure will be dictated by the offender who is least able to respond to verbal signals and that surely cannot be right.' The worry, recall, is that imposing hard treatment on someone who has recognised their offence and is genuinely remorseful and repentant, on the grounds that this imposition is appropriate for offenders who do not and are not, is both unfair, and can only be justified on extrinsic grounds, such as the need for proportionality in sentencing. But it seems inappropriate to punish someone who is genuinely remorseful on the grounds that another offender is not.

\footnotetext{
${ }^{30}$ There are, of course, significant differences between groups, collectives and states. Groups and collectives suggest a level of informality, whereas states are institutional structures. Nevertheless, institutional structures can arguably have beliefs, values and other attitudes: for instance, the University of Glasgow values educational opportunities for all, the pursuit of knowledge and understanding, and so on. In the UK Parliament, it is often said that 'this House believes', etc. Small-scale groups can also be institutional: think of the golf club, with its rules and regulations. So the differences of scale between groups and states don't, I think, undermine the central point that I'm making here. Thanks to the editors of this volume for pushing me to say more on this issue.
} 
There are two responses we might make to this objection. The first acknowledges that certain emotions - such as aesthetic emotions - lack an 'actional' element, but insists that the emotions involved in expressing censure are not of this category. Instead, they are precisely the kinds of emotions that have a behavioural response at their heart: emotions such as anger, a sense of justice, compassion for the victims of crime, and so on. Not all emotions require behavioural expression, therefore, but arguably those involved in censure and condemnation do. If so, then censure and the imposition of hard treatment do not come apart.

A second response admits (for the sake of argument) that censure and actional elements can diverge, but maintains that this does not entail that the imposition of hard treatment is unfair. For if censure expresses appropriate emotion, and if hard treatment is an appropriate behavioural expression of this emotion, then the imposition of hard treatment would seem to be warranted, even if it is not required. The fact that censure need not involve the imposition of hard treatment - the fact that in some circumstances words and facial and bodily expression might be enough to express censure - does nothing to undermine the appropriateness of hard treatment when it is imposed. For since such an imposition is a perfectly appropriate way for emotion to be expressed, then the offender can have no grounds for complaint about its imposition, and so the imposition cannot be in some way unfair or unjust. Consider again the case of Alice and Ted. Perhaps it is possible for Alice to express censure verbally, provided that enough of the other components of emotion are in place; perhaps, then, she doesn't need to give Ted the cold shoulder, ask him to leave the flat for a period of time, and so on. Nevertheless, since such behaviour is an entirely appropriate way for Alice to express her anger, Ted could hardly have any complaints if Alice did behave in this way. He might count himself fortunate in a situation where Alice does not do so, but is in no position to object to treatment that is merited by his bad behaviour. This remains true even if Ted fully recognises his wrongful behaviour, and is fully remorseful and apologetic, as a result of verbal censure. Even in this instance, Ted will have no grounds to complain if Alice also gives him the cold shoulder.

Something similar can be said about the judicial case. Even if censure need not involve the imposition of hard treatment, the offender is in no position to object should the state impose such treatment - given that the state's anger is merited by the wrongdoing, and the imposition of hard treatment is an appropriate behavioural expression of that anger. Such treatment is an intrinsically appropriate response to wrongdoing, therefore. This remains true even if the offender fully recognises his offence, and is fully remorseful and apologetic. Moreover, given the extrinsic benefits of hard treatment - both in terms of increasing the likelihood of recognition and apologetic reparations in most cases of offence, and in terms of the deterrent effect on others - there are additional reasons for the state to impose hard treatment that go beyond its intrinsic appropriateness. 
So even if the imposition of hard treatment is not strictly necessary for the expression of censure, there might nevertheless be good intrinsic and extrinsic reasons to do so.

\section{Conclusion}

The communicative theory of punishment, especially as that theory is formulated by Antony Duff, maintains that hard treatment is an intrinsically appropriate response to criminal wrongdoing. Matt Matravers questions this account, and maintains that the imposition of suffering is at best a focusing device to enable offenders to 'hear' the censure that can be fully expressed by words alone. But I think that Matravers is wrong on this point. Words alone will not express censure, unless they are also expressive of the emotional responses that are themselves merited by wrongdoing. Since emotional responses involve appropriate behaviour, then such behaviour is itself merited or warranted by wrongdoing. On a strong version of this response, this means that censure and hard treatment do not come apart. On a weaker version, then it is possible for censure and hard treatment to diverge, but the offender is in no position to complain about its imposition. Either way, Duff is right in thinking that hard treatment is an intrinsically appropriate response to wrongdoing. The communicative theory can therefore explain why it is legitimate for the state to make offenders suffer through the intentional imposition of hard treatment.

\section{References}

Bedau, H and Kelly, E (2015) 'Punishment' in The Stanford Encyclopedia of Philosophy (Winter 2017 Edition), Edward N Zalta (ed). Available at https://plato.stanford.edu/ archives/win2017/entries/punishment/.

Blum, L (2020) “Black Lives Matter": Moral Frames for Understanding the Police Killings of Black Males' in A Amaya and M Del Mar (eds) Virtue, Emotion and Imagination in Law and Legal Reasoning (Oxford, Hart Publishing).

Brady, MS (2013) Emotional Insight (Oxford: Oxford University Press).

Brady, MS (2018) Suffering and Virtue (Oxford: Oxford University Press).

Duff, RA (2001) Punishment, Communication, and Community (Oxford: Oxford University Press).

Duff, RA (2003) 'Probation, Punishment and Restorative Justice: Should Altruism be Engaged in Punishment?' 42(2) The Howard Journal of Criminal Justice 181.

Duff, A and Hoskins, Z (2018) 'Legal Punishment' The Stanford Encyclopedia of Philosophy, Edward N Zalta (ed). Available at https://plato.stanford.edu/archives/fall2018/entries/ legal-punishment. 


\section{Michael S Brady}

Gray, D (2010) 'Punishment as Suffering' 63(6) Vanderbilt Law Review 1619.

Hansberg, O (2020) 'Empathy and Negative Intimacy' in A Amaya and M Del Mar (eds)

Virtue, Emotion and Imagination in Law and Legal Reasoning (Oxford, Hart Publishing).

Hart, HLA (1968) Punishment and Responsibility: Essays in the Philosophy of Law (New York: Oxford University Press).

Hobbes, T (1651/2008) Leviathan (Oxford: Oxford University Press).

Matravers, M (2011) 'Duff on Hard Treatment' in R Cruft, M Kramer and M Reiff (eds)

Crime, Punishment, and Responsibility: The Jurisprudence of Antony Duff (Oxford: Oxford: Oxford University Press) 68.

Smith, M (1995) The Moral Problem (Oxford: Blackwell Publishers).

White, EK (2020) 'On Emotions and the Politics of Attention in Judicial Reasoning' in A Amaya and M Del Mar (eds) Virtue, Emotion and Imagination in Law and Legal Reasoning (Oxford, Hart Publishing). 